\title{
Problems of legislation as exemplified by the concept of artificial intelligence
}

\author{
Igor Nikolaevich Tarasov* \\ Department of Civil Procedure, Ural State Law University, Ekaterinburg, Russia
}

\begin{abstract}
The number of times the phrase "artificial intelligence" is used both in science and in legislation makes it impossible to carelessly and arbitrarily use this category in governing public relations. It is this circumstance that forces us to turn to the terminology and legislation encapsulated in this category. The paper analyzes current approaches to the concept of artificial intelligence in the legal literature. The author shows that any concept in law and beyond is genetically associated with our knowledge of the object and concludes that reasoning about artificial intelligence is impossible in law until it is clearly defined in technical fields of science.
\end{abstract}

\section{Introduction}

Law in general and, as a consequence, statutory imperative form of action in particular has formal security.

This property suggests that regulating through semiotic units (concepts, definitions, terms, legal constructions, etc.) should be as unambiguous and definite as possible. It is these semantic units that represent individual elements of the legislation. It is important that the element is not only referred to as a semantic component, but also as a symbolic component, since a gap between the sign and the meaning implies that there is no legal regulation.

\section{On concepts in law}

It seems reasonable to explain that a concept expresses the substance of a phenomenon, is a reflection of the universal and essential residing in objects. The concept is seen as a vehicle and result of scientific thinking, which develops conceptually and serves as a concentration of knowledge in a domain.

Categories are the most general concepts that characterize an object of study, and it is necessary to remember that the degree of generalization of categories should be limited by the boundaries of the object as such. In this sense, categories serve as a way of organizing knowledge already acquired about the object.

The definition, though, indicates a framework within which the concept is to be applied, by listing some essential features that are needed to establish the merits of the concept.

"Dealing with legal categories, we do not study a legal form of social life at large, but the knowledge accumulated by legal science about it, a system of concepts that reliably mirrors legal reality and objective reasoning behind its functioning and development" [1].

Concepts in law can come up in three main ways:

1) resulting from professional reflection, when a concept is developed and a sign (term) is assigned to it based on comprehension of current legal processes by individuals within the profession;

2) being borrowed from other branches of social life, with a change in the content of the concept;

3 ) being borrowed from other societal spheres of without changing the content of the concept [2].

In this case, addressing borrowed concepts that greatly change, we say that a certain linguistic unit is being filled with a new semantic meaning. However, once incorporated into professional paradigm, a semantic unit is not just giving a new content to a word, but involves coordinating this unit with already existing concepts and categories, and also involves "processing" the meaning of the semantic unit being defined, built following the rules of legal thinking.

In modern law, such processing and filling with new meaning basically leads to a legally correct definition of a new phenomenon, which is integrated into the terminology, being sensitive to its attributes.

Without elaborating a legal definition of artificial intelligence, the legislation governing the use of appropriate technology in legal proceedings can be accidentally effective, if at all.

\section{Definition of Al}

When it comes to the definition of AI, first of all, it is reasonable to refer to the legal definition enshrined in Decree No. 490 of the President of the Russian Federation dated October 10, 2019 On the Development

Corresponding author: tarasov.igor.n@gmail.com 
of Artificial Intelligence in the Russian Federation. AI is defined as a set of technological solutions to simulate human cognitive functions (including self-learning and search for solutions without a preconceived algorithm) and, when performing specific tasks, obtain results comparable, at least, to intellectual products. The set of technological solutions includes information and communication infrastructure, software (including MLbased), processes and services for data processing and decision making.

By its nature, attributive (mandatory) features, this legal definition is believed to be naturally scientific, since it lists a number of non-legal features and characteristics of artificial intelligence. In addition, this definition does not contain a reference to any legal structure, which could determine the legislator's decision regarding the position (within the framework of any classification or typology) to be taken by $\mathrm{AI}$ in the legal system. All this suggests that this definition has no legal meaning and merely declares some technical properties of the substance of the legislation.

Today, many different definitions of AI have been provided in the literature. Some of them are descriptive in technical terms [3-6].

The common problem of all the above definitions proposed by the authors is that these definitions are nonlegal (technical), i.e. articulated not within a legal paradigm, but in the rules, concepts and categories used by technical specialists in this domain.

It is for this reason that these definitions do not bring any clarity to getting aware of the nature and substance of artificial intelligence from the point of view of the science of law. The above definitions convey no relation of the described phenomenon to the law, and, therefore, this definition does not make any sense for the law and cannot serve as a basis for any subsequent conclusions or analysis.

In addition to technical approaches to understanding AI, the literature also presents some points of view that are united by one or more attributes. For the convenience of analysis, these approaches are combined into groups.

3.1. The first approach implies treating AI, similarly to a legal entity, as a kind of legal fiction.

Some authors believe [7-9] that the approach is one of the most promising and sound.

The approach suggests applying the theory of legal entity to AI with some refinements, tailored to AI.

Thus, according to Arkhipov V.V. and Naumov V.B. this approach allows selective application of civil law provisions that govern legal relations involving legal entities to legal regulation of robots in a similar way [7].

According to the authors, the similarity is based on the artificial nature of legal entities and robots.

First of all, it seems that the authors compare "red with Thursday", because the artificiality of robots and the artificiality of legal entities (this, by the way, is generally questionable) are completely different concepts.

It is not quite clear what exactly the group of authors means by this approach, since this interpretation is deemed to be completely pointless.
One thing alone can be definitely deduced from this approach - the authors propose to give AI the status of a party to a legal relationship.

It is important to understand that in order to define the legal capacity of any civil entity, it is necessary to figure out whether it has the will to perform certain actions significant for the legislation. With a view to applying these concepts to robots empowered with advanced artificial intelligence and autonomy, some researchers argue that such systems have a civil will [7].

The approach secured by such argumentation demonstrates a complete inconsistency, since it is proposed to perceive AI as a kind of legal entity, but at the same time, it is based on the fact of will, which a) absolutely has nothing to do with legal entities b) is not decisive even for defining an individual before the law, not to mention the fact that animals like dogs also have the will. However, for some reason they not come under a legal person.

3.2. The second approach suggests considering AI as an agent (e-person) [10-12][7][13].

The approach consists in creating a special legal framework assuming that an e-person will have subjective rights and legal obligations, be a set of such rights and obligations, the content of which is the actions of artificial intelligence [8].

Under this approach, "e-person" is viewed as a new legal person whose name should reflect its substance and legal specificity.

Thus, O.A. Yastrebov proposes to consider artificial intelligence as a basic component of e-person, which predetermines this idea to be used for defining a legal status of robots [8].

The authors believe that e-persons (difficulty in framing their legally significant behavior) determines the need to form a fundamentally new legal toolkit. To put the approach into practice, it is not necessary to work out a new layer of legislation, since relations involving legal entities are legally regulated by the current legislation [8].

In this regard, a question comes up about liability for non-compliance - the robot-agent as a legal or electronic person or the developer of technology for the robot to perform its actions.

P.M. Morkhat considers it quite appropriate to recognize $\mathrm{AI}$ as an individual before the law. And the new concept of e-person allows this to be realized.

Empowering AI units with legal standing will be that such devices will have not only rights, but also responsibilities. What is more, endowing an actor with legal standing aims to allow them to have certain legal implications of their actions and to feel the effects of law [9].

With the approach, a question comes up as to why is it proposed to introduce a new construct in the form of an e-person? The authors appeal to the fact that a number of conventions and fictions have already been used in law, so why not introduce another one?

However, the construct of a legal entity results from a long-term understanding of the law for the purpose of new economic conditions. 
G.F. Shershenevich highlights that thanks to a legal entity interests shared by many individuals, as well as legal instruments, become isolated; creating such a person (legal) not only saves the harmony of legal concepts, but also facilitates the achievement of that vital need for which property is isolated [14].

The construct of a legal entity pursued a direct economic goal and allowed the law to better regulate economic relations developing without its direct participation.

It should be borne in mind that the science of law offers a teleological approach, by which it is necessary to analyze why we introduce this or that concept into law.

A new category introduced in law is likely to be redundant, as there is another category or structure regulating this direction.

In addition, a moment to change in the legislation is important for the discussion and development of a concept. How will the legislation change as long as the concept of AI is introduced?

In order to answer this question, first of all, there should be a clear idea of what exactly needs regulating, and this requires a clear technical description of $\mathrm{AI}$ as a phenomenon and its activity.

Applying some knowledge followed by a concept derived is possible provided that we analyze the activity associated around this knowledge.

All the definitions and approaches to understanding AI described above are similar to sociological methods in law, which are characterized not only and not so much by the rule of law, but also largely take into account economic, political, opportunistic and psychological factors that should influence regulation or the resolution of a particular situation.

Such a sociological approach is most typical for countries with a system of common case (Anglo-Saxon) law. It cannot be said that these methods and bases underlying the legal regulation of the Anglo-Saxon system of law are negative. However, as S.S. Alekseev noted rightly, "sociological" orientations in jurisprudence ... lead to the fact that the very phenomenon of law is lost to some extent." [16].

In other words, these approaches may reflect one aspect of this phenomenon, but this reflection cannot be considered from the point of view of using it as a basis for building legal regulation.

The Romano-Germanic family of legal systems is more prone to detailed, fragmentary study and identification of the content, meaning of legal norms, ascertaining the essential features, characteristics and principles of interaction. All this made it possible to create a unified conceptual and categorical apparatus of the phenomenon of legal reality.

\section{Conclusions about the origin of the concept}

G.P. Shchedrovitsky dwells upon the genesis of the concept and its connection with the definition. It is his approach to this issue that seems the most reasonable.
A concept is general knowledge about something. General in this case implies much knowledge about a certain subject and this knowledge of the subject coincides.

The concept arises only when there is a certain set of objects for which the signs A and B to be present in all objects are verified and some general meaning is fixed that $\mathrm{A}$ is $\mathrm{B}$. This is how knowledge about the object originates.

In order for this knowledge to be transformed into a concept, it is necessary to develop a common formal bond: formal because it is out of the object; common because once the bond is developing, its availability in each element is checked.

And only then can we talk about the development of a concept [15].

Thus, to let us reflect as lawyers or even just ordinary people about AI (assuming that lawyers are not driving experts in the field of AI), we need AI, about which we could form common, single knowledge for each observer.

As soon as we all establish that A, B, C are inherent in all AIs, we will receive knowledge about a real object - AI. And when this knowledge is out (demeaned) of the object and a connection is established with each element of knowledge, we will talk about the development of the concept of AI.

In this case, we deliberately say that it is the definition of the concept of AI that is being formed. The definition should be perceived not only as a process of developing an approach to the concept, but also as its result, often referred to as a definition.

In logic, it is customary to divide all definitions into nominal and real ones.

Nominal definitions indicate the meaning of the term. Nominal definitions, as a rule, are used to clarify a term already introduced into the language of science or natural language.

Thus, in the nominal definition, "the term in the function of mentioning it" is defined [17, p. 15].

In real definitions, the object itself is determined, in other words, through a real definition, the object of interest to us is separated from other objects in the corresponding area.

Thus, in a real definition, "an object (real, abstract or imaginary) is defined, since the term corresponding to this object is used in the function of its use" [17, p. 15].

It seems indisputable that at this stage of the emergence of $\mathrm{AI}$, the primary task when we talk about the formation of the definition of $\mathrm{AI}$ is the ability to define AI in a mass of similar objects, that is, the formation of a real definition.

As V.S. Nersesiants noted, "in the process of scientific study, the initial empirical knowledge about the object is supplemented by theoretical knowledge, i.e. a system of concepts about the main essential properties and characteristics of the object under study, about the laws of its genesis, functioning and development. Scientific (theoretical) cognition is thus a creative process of deep comprehension of the object under study in thinking, in the creation of its mental image (model) 
in the form of a certain system of concepts about the essential properties of this object" [18].

It seems that the object for the analysis of the science of law and legal regulation as a whole may initially be a definition that will be formed not by lawyers, but by specialists in the field of AI.

Such a definition would make it possible to get an idea of the actual properties and characteristics of the phenomenon analyzed for the purposes of legal regulation and the science of law, and in the future would also allow to develop a legal definition and understanding of AI through the use of existing epistemological tools of the science of law.

One of the problems of incorporating $\mathrm{AI}$ into existing law is that AI does not work with the content of concepts and categories, which makes it impossible to work in law, since the current model is largely built on the meaningful (semantic) relationship of concepts.

Most of the definitions and approaches proposed in the legal literature seem to be either a listing of individual technical characteristics given by nonspecialists (lawyers) in the field of AI, or an attempt to form legal structures without taking into account the specifics of the analyzed phenomenon.

Such negligence in approaches leads, in our opinion, either to a senseless comparison of different-order and different-volume categories, which excludes the possibility of verifiable and reliable conclusions, or to the formation of proposals on the legal regulation of AI, without understanding the purpose of legal regulation, but solely in order to "come up with" something in connection with the emergence of a category of AI unfamiliar to the authors.

In our opinion, the incorporation of $\mathrm{AI}$ into the ontology of law is possible within the framework of two main approaches:

1) Conceptualistic - when understanding the properties and knowledge about $\mathrm{AI}$ as an object of the real world, with the subsequent derivation of a legal definition based on this knowledge about the object.

2) Regulatory - when the legislator assigns a certain legal status to AI, regardless of its actual properties and characteristics (by analogy with assigning the status of real estate to aircraft and ships).

However, without defining the approach, without analyzing the properties and characteristics of AI as a technical and cultural phenomenon, discussions about preventive regulation are, to put it mildly, unreasonable and not based either on science or the law of action.

Once the concept is developed, we will be able to move on to articulating the definition of $\mathrm{AI}$ and understanding the place of AI in the gist of law.

Only in this way can the legal world initiate attempts to comprehend this phenomenon for the purposes of law.

Until then, any discussion about preventive regulation is, to put it mildly, unfounded and not based on either science or the law of action.

\section{References}

1. A.M. Vasiliev, Legal categories (Legal literature, Moscow, 1976)

2. N.N. Tarasov, Methodological problems of legal science (Ekaterinburg, 2001)

3. I.V. Ponkin, A.I. Redkina, Artificial intelligence from the point of view of law, Bulletin of the Peoples' Friendship University of Russia. Ser.: Legal sciences, 1(22) (2018)

4. R.F. Zakirov, The use of modern IT as a means of achieving the main objectives of legal proceedings, Herald of Civil Procedure, 1 (2018)

5. Yu.S. Kharitonova, Legal regime of the results of artificial intelligence, Modern information technology and law: monograph (Statute, Moscow, 2019)

6. V.A. Laptev, The concept of artificial intelligence and liability for its functioning, Law. Journal of Higher School of Economics, 2 (2019)

7. V.V. Arkhipov, V.B. Naumov, On some issues of theoretical foundations for legislation on robotics: aspects of will and legal standing, Zakon [Law], 5 (2017)

8. O.A. Yastrebov, Legal standing of an electronic person: theoretical and methodological approaches, Proceedings of the Institute of State and Law of the Russian Academy of Sciences, 2 (2018)

9. P.M. Morkhat, Artificial Intelligence Unit as an Electronic Person, Bulletin of the Moscow State Regional University. Series: Jurisprudence, 2 (2018)

10. E.N. Iriskina, K.O. Belyakov, Legal aspects of civil liability for harm caused by the actions of a robot as a quasi-subject of civil law relations, Humanitarian informatics, 10 (2016)

11. P.M. Morkhat, Legal standing of AI in the field of intellectual property law: civil law problems: Doctoral Dissertation (Moscow, 2018)

12. E.P. Sesitsky, Problems of legal protection of results created by AI systems: Candidate Dissertation (Moscow, 2018)

13. A. Gurko, Artificial intelligence and copyright: an insight into the future, IP. Copyright and related rights, 12 (2017)

14. G.F. Shershenevich, Textbook of Russian civil law (SPARK, Moscow, 1995)

15. G.P. Shcherdrovitsky, Selected Works (School of Cultural Policy, Moscow, 1995)

16. S.S. Alexeev, Ascending to the right. Searches and solutions (Moscow, 2001) p. 9.

17. D.P. Gorskiy, Definition (Moscow, 1974) pp. 5-16.

18. V.S. Nersesiants, Jurisprudence. Introduction to the course of the general theory of law and state (Moscow, 1998) p. 58. 